\title{
Cadmium Uptake, Growth and Phytochelatin Contents of Triticum Aestivum in Response to Various Concentrations of Cadmium
}

\author{
Sonya Hentz, Jacqueline McComb, Gloria Miller*, Maria Begonia, Gregorio Begonia \\ Plant Physiology/Microbiology Laboratory, Department of Biology, P.O. Box 18540, College of Science, Engineering and Technology, \\ Jackson State University, 100 Lynch Street, Jackson, Mississippi 39217, USA
}

\begin{abstract}
Cadmium (Cd) contamination of the environment is a major concern because of its impact on human health, food supply chain, and ecosystems. Phytoremediation has emerged as an alternative technology to expensive engineering techniques. The objectives of this research were to evaluate the growth and cadmium uptake of wheat (Triticum aestivum $\mathrm{L}$. cv TAM 109) plants exposed to Cd at different periods; and assess whether phytochelatin (PC) synthesis can explain the wheat's tolerance mechanism to cadmium. Wheat seeds were grown in sand medium for 30 days (pre-metal treatment). After initial exposure to different $\mathrm{Cd}$ concentrations using hydroponic systems, plants were harvested at different day intervals, separated into roots and shoots, dried at $75^{\circ} \mathrm{C}$ for 2 days, weighed for dry biomass, and acid-digested for cadmium uptake determinations. Cadmium uptake and PC contents of roots and shoots were quantified using established procedures. Results showed that shoot and root biomass increased with exposure time, and was more pronounced in the shoot than in the roots. Shoot $\mathrm{Cd}$ uptake increased with increasing $\mathrm{Cd}$ concentrations, except at days 8, 12, and 15 wherein $\mathrm{Cd}$ uptake was very minimal especially at $20 \mu \mathrm{M}$. Root Cd uptake increased with increasing exposure periods and Cd concentrations. The syntheses of PC in shoots were significantly enhanced only at $20 \mu \mathrm{M} \mathrm{Cd}$. There were no significant differences in quantity of roots' $\mathrm{PC}$ regardless of Cd treatments.
\end{abstract}

Keywords Cadmium, Phytochelatin, Phytoextraction, Triticum aestivum

\section{Introduction}

Phytoremediation is the use of living plants for the removal of contaminants from contaminated soil, water, sediments, and air. Soil contamination by heavy metals (HMs) is an important environmental concern because these heavy metals are often persistent in the soil, due to their immobile quality[1]. In minute amounts, many of these heavy metals are essential to sustain life. However, in larger amounts, they become toxic to the environment. The addition of phosphorus fertilizers that often contain a variety of metals especially $\mathrm{Cd}$, is largely responsible for the increasing $\mathrm{Cd}$ capacity in agricultural soils[2]. Cadmium in the environment has the capability to bioaccumulate in the body. Cadmium may assemble in biological structures and becomes a substantial health hazard. Prolonged exposure to metals such as cadmium could cause acute and chronic diseases including acute gastrointestinal, respiratory, heart, brain and kidney damage[3]. Phytoremediation is an

* Corresponding author:

gloria.s.miller@jsums.edu (Gloria Miller)

Published online at http://journal.sapub.org/env

Copyright (C) 2012 Scientific \& Academic Publishing. All Rights Reserved emerging technology that is correlated indirectly to human health, the food supply chain, and the aquatic and terrestrial ecosystem. The transmission of metals from waste products to the soil and afterwards to plants pose potential danger in which immediate action needs to be taken to eradicate the problem[1]. Generally, heavy metals also impact soil productivity and these contaminated soils are costly to remediate by conventional methods (e.g., removal and burial, or isolation). The major pathway in which heavy metals enter the food supply chain is through plant uptake via the root system. Using plants (phytoremediation) as a clean-up strategy has emerged as a cost-effective and environmentally benign alternative method[4].

A major aim of current phytoremediation research is to identify metal-tolerant plants that are able to uptake and translocate heavy metals to their above ground parts (shoots) for easier harvesting[5]. The distribution of heavy metals from the environment to plants for phytoextraction depends on three factors: the total concentration, the bioavailability of elements in the soil solution, and the rate of the element transfer from solid to liquid phases and then to the plant roots[3]. Heavy metal stress can cause direct and indirect consequences to biological processes in plants. The detoxification mechanisms of heavy metals modify catalytic func- 
tions of enzymes, and damage cellular membranes[3]. These changes in plants may initiate several preliminary effects, such as inhibition of photosynthesis, mineral nutrient accumulation, root and shoot growth, demineralization, as well as hormonal imbalance and water stress[3]. There is a difference in accumulation of heavy metals depending on their biochemical actions and metal concentrations even for plants of the same species[6]. The success of phytoextraction techniques depends upon appropriate plant species that can accumulate heavy metals and yield large amounts of biomass[5]. Even though total plant biomass is an important factor for phytoextraction, preferential metal accumulation in plant shoots is of utmost importance, therefore the use of hyperaccumulators is significant for phytoextraction of heavy metals in polluted soils.

Phytochelatin (PC) synthesis is one of the responses exhibited by plants exposed to HMs, and it is a useful biomarker, reflecting plant's actual exposure to excess internal HM content[7-9]. A key question however, is whether there has to be a critical minimum limit of heavy metal in plants, before PCs start to form. Also, the use of chelating agents has been proposed to achieve higher removal rates of metals. The use of these synthetic chelators such as Ethylenediamintetraacetic acid (EDTA), can pose environmental concerns because of their high solubility and persistence in the soil. However, Ethylenediamine- $N, N^{\prime}$-disuccinic acid (EDDS), an EDTA isomer is easily biodegrable and has less deleterious effect on the environment[10].

Wheat (Triticum aestivum) is the plant of primary importance chosen for this research. It is a monocot plant whose stems contain various cells (parenchyma, and sclerenchyma) that aid in the capacity of the plant to withstand stress factors[11]. These types of plants also exhibit an intercalary meristem that contributes to the stem strength[11]. Wheat plants may also be grown year round and during the colder seasons which suggest that these plants can withstand harsh environmental conditions. Wheat has a fibrous root system that helps hold soil particles together and aid in the accumulation of heavy metals. While most metals have toxic effects and act as persistent pollutants in the environment, cadmium and lead are metals of primary importance[12] and are ranked second and seventh, respectively, on the Comprehensive Environmental Response Compensation and Liability Act (CERCLA) priority list of hazardous substances due to their wide spread distribution, availability, and toxicity[13]. This study was conducted to: 1) evaluate the growth and $\mathrm{Cd}$ accumulation by wheat (Triticum aestivum L. cv TAM 109) plants exposed to various levels of Cd (supplied as cadmium nitrate) at different growth periods, 2) determine whether wheat (Triticum aestivum L.) plants can tolerate and translocate high concentrations of cadmium, and 3) assess phytochelatin (PC) synthesis in Triticum aestivum L. exposed to Cd.

\section{Materials and Methods}

\subsection{Growth Conditions}

Wheat (Triticum aestivum L. cv. TAM 109) seeds (72 seeds/pan) were sown in $42.2 \mathrm{~cm}$ x $30.2 \mathrm{~cm}$ x $6.7 \mathrm{~cm}$ JiffyFoil pans containing sand (Showscape Play Sand). Germinated seedlings were maintained for 30 days at the Jackson State University greenhouse. During this 30-day pre- treatment period, the plants were watered with tap-water twice a day (once in the morning and again in the afternoon). After the 30-day growth period, the seedlings were acclimated by irrigating them with $40 \mathrm{~mL}$ of modified Hoagland's nutrient solution, which contained the following nutrients in $\mathrm{mM}$ : calcium chloride dihydrate, 2.0: potassium orthophosphate mono-H, 0.125: magnesium sulfate heptahydrate and potassium sulfate, 0.50: Fe sequestrene, 10.0: ammonium nitrate, 2.50; the following are in $\mu \mathrm{M}$ : boric acid, 2.30: manganous sulfate monohydrate, 0.9 : zinc sulfate heptahydrate, 0.60 : cupric (copper II) sulfate pentahydrate, 0.15: sodium molybdate dihydrate, 0.10 : cobalt (II) chloride hexahydrate, 1.0: nickel chloride hexahydrate, 0.10 .

During the 30-day growth period, each pan was rotated counter clock wise to ensure that all plants received adequate amounts of sunlight (i.e. no positional effects). After the plants were allowed to go through their vegetative stage, plants were selected for uniformity. Sand particles adhering to the roots of each plant were carefully washed with tap water. Clean plants (4 plants $/ 600 \mathrm{~mL}$ styrofoam cup) were placed in designated dilute solution of cadmium nitrate $(0$, $0.1,1.0,5.0,10.0,15.0,20.0 \mu \mathrm{M} \mathrm{Cd})$. Each plant was secured by wrapping its stem base with cotton to ensure that the plants remained upright with the roots fully immersed in the solution. Plants were irrigated with modified Hoagland's solution as needed to replenish the volume lost through evapotranspiration. Cadmium mixtures were agitated daily to make sure the metal remained suspended in the solution.

The plants were harvested at designated intervals (e.g., 0 , $2,5,8,12,15$ days) after treatment initiation. Plants for time 0 were allowed to remain in the metal mixture for 6 hours and then removed. The remaining times where harvested according to their respective days. The harvested plants were rinsed with deionized water to remove any metal that may have been adhering to the root epidermis. They were then towel blotted and placed in a specimen cup. Two plants were harvested for phytochelatin analysis. The roots and shoots where separated and segregated parts (roots and shoots) of each plant were placed in a $15 \mathrm{~mL}$ BD Falcon tubes and placed in a Thermo Electron Corporation Forma $-80^{\circ} \mathrm{C}$ ULT Freezer. The remaining two plants were separated into roots and shoots and analyzed for morphological characteristics (biomass and length, length data not shown).

\subsection{Acid Digestion}

The segregated plant parts were placed in corresponding labeled brown paper bags and dried in a Precision Mechanical Convection Oven at $70^{\circ} \mathrm{C}$ for at least 48 hours. 
Dried samples were weighed in a Mettler AE 260 Delta Range to obtain the biomass. Cadmium contents from plant tissues were extracted using a modified nitric acid-hydrogen peroxide procedure according to U.S. Environmental Protection Agency[14] EPA SW-846 Method 3040B. Approximately $100-200 \mathrm{mg}$ of dried tissue plant samples were placed in a $250 \mathrm{~mL}$ Erlenmeyer flask and $40 \mathrm{~mL}$ of $50 \%$ nitric acid were added and allowed to set overnight. Samples were placed on a hot plate (high setting) and refluxed for 15 minutes until a yellow liquid appeared. The solutions were allowed to cool for 10 minutes and $10 \mathrm{~mL}$ of $50 \%$ nitric acid $\left(\mathrm{HNO}_{3}\right)$ were pipetted into each sample. The samples were refluxed for 30 minutes and then allowed to cool for 10 minutes. The samples were completely dissolved in $5 \mathrm{~mL}$ of concentrated nitric acid. The oxidized solution was allowed to cool and $2 \mathrm{~mL}$ of deionized water and $3 \mathrm{~mL}$ of $30 \%$ hydrogen peroxide were added. The digested solution was heated until the effervescence diminished. Another $7 \mathrm{~mL}$ of $30 \%$ hydrogen peroxide were added in $1 \mathrm{~mL}$ intervals and the digestate was heated again and reduced to approximately $5 \mathrm{~mL}$. After heating, the solution was diluted to $20 \mathrm{~mL}$ with deionized distilled water (ddw) and the digestate was filtered through filter paper (Whatman No. 1) and the final volume was adjusted to $25 \mathrm{~mL}$ with ddw. Cadmium contents of each sample were quantified using Inductively Coupled Plasma-Optical Emission Spectrometry (Perkin Elmer Optima 3300 DV).

\subsection{Phytochelatin Synthesis Analysis}

According to Keltjens and Van Beusichem[15] plant parts (roots or shoots) were homogenized separately for 5 minutes in $10 \mathrm{~mL}$ of extraction mixture with a mortar and pestle on ice under nitrogen gas to prevent oxidation. The homogenates were placed in centrifuge tubes and cooled on ice. When twelve tubes filled with wheat homogenate were collected, they were centrifuged in a Beckman Optima XL $100 \mathrm{~K}$ Ultra Centrifuge for 15 minutes at 10,000 revolutions per minute $(\mathrm{rpm})$ at $4^{\circ} \mathrm{C}$. The supernatant was then decanted into a $15 \mathrm{~mL}$ BD Falcon tube. Phytochelatin concentrations were determined indirectly by assessing the absorption of total acid-soluble thiols, total glutathione, and oxidized (GSSG) glutathione. The total acid-soluble thiols were determined using Ellman's reagent[16]. Total glutathione and oxidized glutathione were established using GSSG recycling method[17].

\subsection{Statistical Analysis}

The data were analyzed using Statistical Analysis System (SAS V9). Treatment comparisons were done using Fisher's Least Significant Difference (LSD) test $(p<0.05)$.

\section{Results and Discussion}

Shoot biomass analysis revealed that there was a decrease in biomass as the concentration of cadmium administered was amplified as shown in Figure 1. With regard to days after initial exposure to the metal, the shoot biomass increased as exposure time increased. Plants exposed to 20 $\mu \mathrm{M} \mathrm{Cd}$ showed the greatest inhibition of shoot biomass. Plants exposed to $\mathrm{Cd}$ for $5,8,12$, and 15 days were significantly affected as compared to the control $(p \leq 0.016)$. Shoot biomass followed a dose response trend with day 15 showing the greatest level of toxicity at $20 \mu \mathrm{M}$. Days 5 and $8,0.0468 \pm 0.0095$ and $0.0616 \pm 0.0126$; days 2 and 5 , $0.0373 \pm 0.0116$ and $0.0468 \pm 0.0095$; days 0 and $2,0.0303$ \pm .0091 and $0.0373 \pm 0.0116 \mathrm{~g} /$ plant respectively were not significantly affected as compared to each other. Day 15 demonstrated the greatest shoot biomass increase $(0.1130 \pm$ $0.0310 \mathrm{~g} /$ plant). There were similar trends in shoot biomass for increase in treatments and growth periods. Plant shoots exposed to cadmium nitrate at 2 and 5 days after initial exposure remained within the same biomass range, 0.0373 \pm 0.0067 and $0.0468 \pm 0.0055 \mathrm{~g} / \mathrm{plant}$, respectively. Day 8 showed a fluctuation in shoot biomass with an increase for $0.1 \mu \mathrm{M}(0.0794 \pm 0.0050 \mathrm{~g} / \mathrm{plant})$ and then a slight decrease at 1 and $5 \mu \mathrm{M}(0.0635 \pm 0.0044$ and $0.0613 \pm 0.0040$ $\mathrm{g} /$ plant), respectively, followed by an increase at $10 \mu \mathrm{M}$ $(0.0716 \pm 0.0041 \mathrm{~g} /$ plant $)$ and lastly a decrease for 15 and 20 $\mu \mathrm{M}(0.0404 \pm 0.0081$ and $0.0462 \pm 0.0102 \mathrm{~g} / \mathrm{plant})$, respectively. Days 12 and 15 showed a decrease in shoot biomass as the concentration increased and also as exposure time increased.

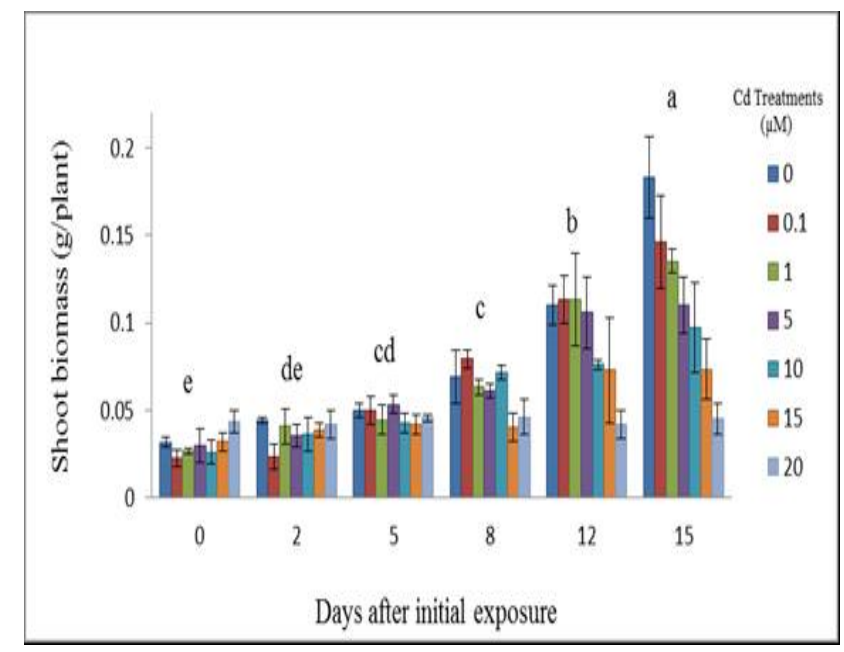

Figure 1. Wheat shoot biomass (g/plant) at 15 days after initial exposure to $\mathrm{Cd}$. Treatment means with common letters do not differ significantly from other days $(p \leq 0.05)$

Figure 2 shows that there was a steady decline in shoot biomass with $20 \mu \mathrm{M}$ exhibiting the greatest reduction as compared to the control. Non-metal $(0 \mu \mathrm{M})$ - exposed plants produced the greatest biomass as expected. The shoot biomass then decreased dramatically ranging from $0.1835 \pm$ 0.0404 to $0.0450 \pm 0.0156 \mathrm{~g} / \mathrm{plant}$. For the growth periods of wheat the control treatments $(0 \mu \mathrm{M})$ were all greater in terms of shoot biomass. There was a significant difference in shoot biomass at $20 \mu \mathrm{M}$ as compared to the control $(0.045 \pm 0.015$ vs. $0.183 \pm 0.040 \mathrm{~g} / \mathrm{plant})$. Day 15 followed a dose response correlation to the corresponding treatments $(0,0.1,1.0,5,10,15,20 \mu \mathrm{M})$. 


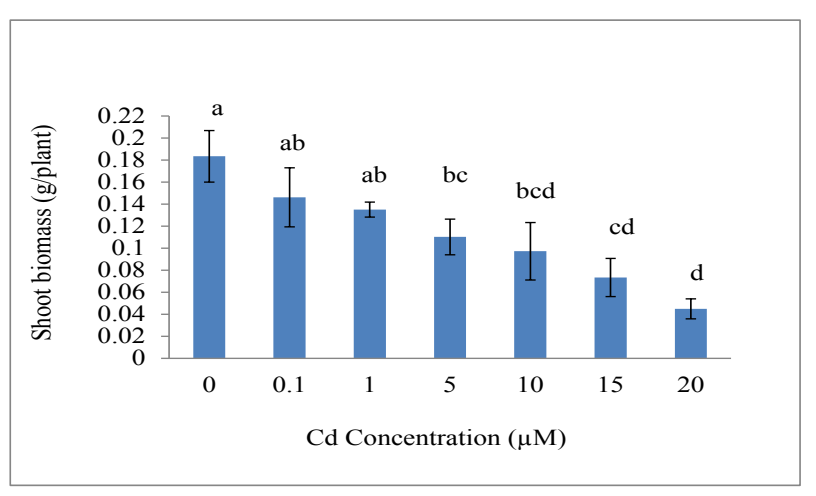

Figure 2. Wheat shoot biomass (g/plant) at 15 days after initial exposure to $\mathrm{Cd}$. Treatment means with common letters do not differ significantly from each other $(p \leq 0.05)$

Figure 3 clearly displays an image of day 15 after initial exposure to cadmium treatments that corresponds with Figure 2. As seen in Figure 3, wheat plants exposed to $20 \mu \mathrm{M}$ of cadmium showed dramatic growth reductions as compared to the control. The image also shows that Triticum aestivum L cv. TAM-109 withstood the toxicity of the metal.

There was a decrease in shoot biomass as cadmium concentrations increased. Figure 3 shows that at concentrations 0 through $1.0 \mu \mathrm{M} \mathrm{Cd}$, the wheat plants were thriving and displaying no form of physiological disarray. Thereafter, there was a gradual decrease in shoot height as concentrations of $\mathrm{Cd}$ treatments increased. At $20 \mu \mathrm{M}$ the plants began to wither and exhibited chlorosis.

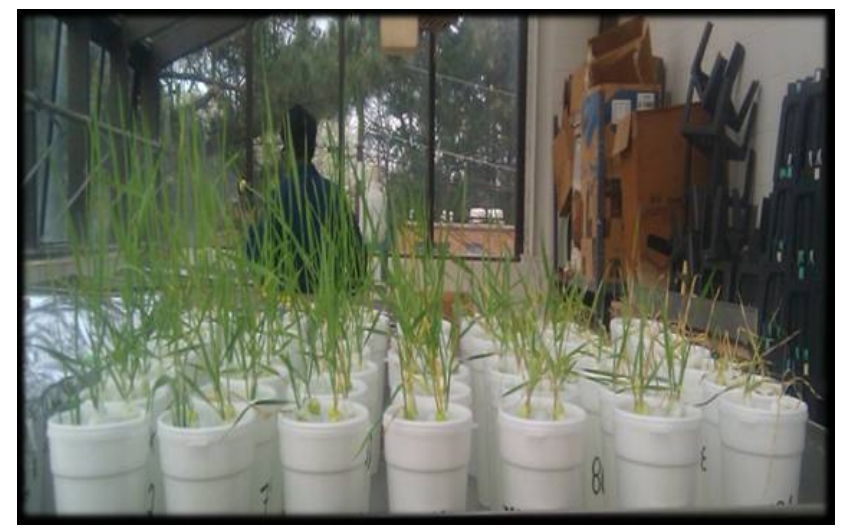

Figure 3. The morphology of Triticum aestivum L. plants at 15 days after initial exposure to different $\mathrm{Cd}(\mu \mathrm{M})$ treatments

Root biomass appeared similar regardless of the exposure time (Figure 4). Root biomass withstood cadmium toxicity starting at treatments $\geq 5 \mu \mathrm{M}$. Day 15 at $0 \mu \mathrm{M} \mathrm{Cd}$ showed the greatest root biomass, $0.0938 \pm 0.0204 \mathrm{~g} /$ plant (Figure 4). Root biomass at day 15 was significantly affected by $\mathrm{Cd}$ treatments as compared to the control. Furthermore, there were no significant differences among days $15,12,8$, and 5 . Root biomass ranged from $0.0938 \pm 0.0204$ to $0.0304 \pm$ $0.0095 \mathrm{~g} / \mathrm{plant}$ from highest to lowest biomass, respectively. Cadmium-exposed plants displayed a decrease in root and shoot biomass compared to the control.

Shoot tissue uptake mirrored closely the uptake by roots, indicating that a proportionate amount of cadmium was being translocated to the above ground biomass. Cadmium uptake by wheat shoots demonstrated an increase in acceptance of Cd for day $12(15729.96 \pm 12421.07 \mathrm{mg} / \mathrm{kg})$. Day 12 revealed a significant comparison from the control (Figure 5).The succeeding harvest days after day 5 revealed an uptake in $\mathrm{Cd}$ till concentration $15 \mu \mathrm{M}$. There were no remarkable shoot uptake for plants exposed to $20 \mu \mathrm{M} \mathrm{Cd}$ for 8,12 , and 15 days (Figure 5). Plants treated with $15 \mu \mathrm{M} \mathrm{Cd}$ displayed the greatest shoot uptake. There was an increasing trend of $\mathrm{Cd}$ uptake as the concentration of $\mathrm{Cd}$ treatment increased. For example at day 8 , concentrations 1 , and 15 $\mu \mathrm{M}, \mathrm{Cd}$ uptake were significantly different as compared to each other $2855.27 \pm 688.96,3965.78 \pm 743.38,10468.73 \pm$ 955.55 , respectively. Root and shoot uptake analyses indicated that the greater percentage of cadmium was sequestered in the roots especially at 12 days after initial exposure. We observed that the uptake $(15491.85 \pm 7323.22 \mathrm{mg} / \mathrm{kg})$ was most remarkable at $20 \mu \mathrm{M}$ after 12 days of exposure (Figure 6). The means of day 12 were significantly different as compared to the means of day 0 .

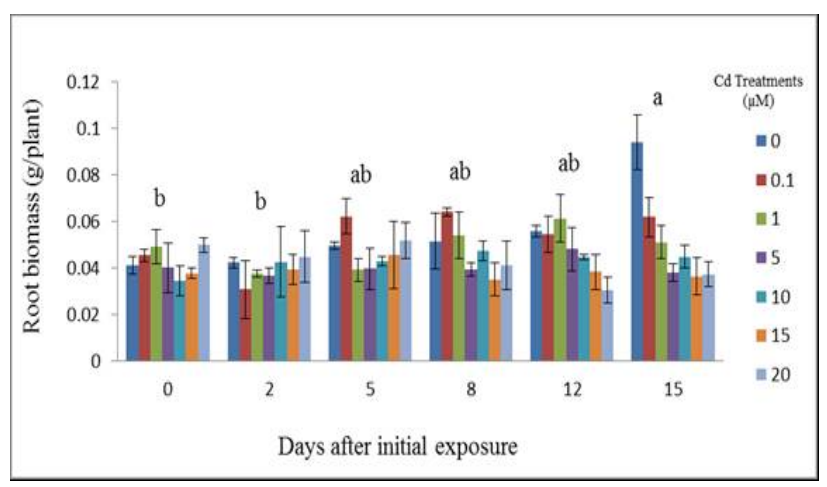

Figure 4. Wheat root biomass (g/plant) at different days after initial exposure to Cd. Day means with common letters do not differ significantly from other days $(p \leq 0.05)$

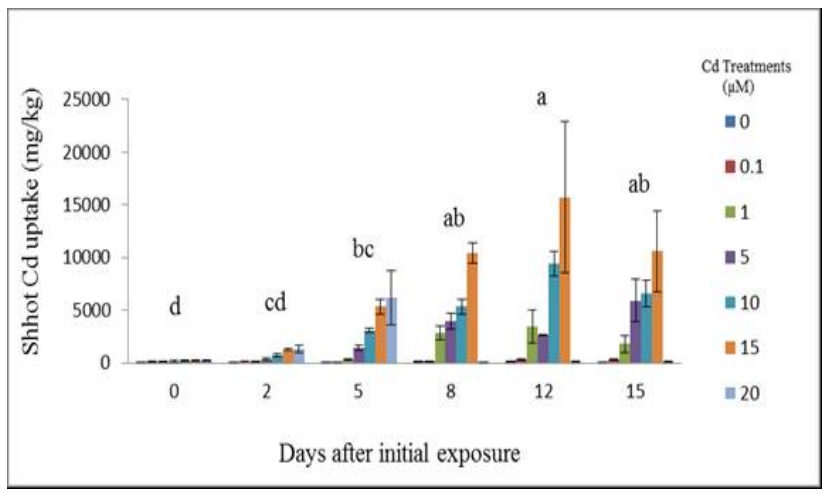

Figure 5. Cadmium uptake by wheat shoots at different days after initial exposure to Cd. Day means with common letters do not differ significantly from other days $(p \leq 0.05)$

There was a consistent increase in root uptake of available Cd until day 12 , with day 15 remaining tolerant to the metal, staying within the range starting at $27.73 \pm 13.87$ until $12974.85 \pm 2163.50 \mathrm{mg} / \mathrm{kg}$ (Figure 6). Day 15 for wheat root uptake showed significantly higher values for treatments 10,15 , and $20 \mu \mathrm{M} \mathrm{Cd}$ as compared to the control. Figure 6 shows that wheat plants exposed to $20 \mu \mathrm{M} \mathrm{Cd}$ se- 
questered most of the $\mathrm{Cd}$ in their roots. The consequence of this $\mathrm{Cd}$ sequestration in the roots exposed to $20 \mu \mathrm{M} \mathrm{Cd}$ led to limited $\mathrm{Cd}$ shoot uptake, especially for plants exposed to Cd treatments for 8,12 , and 15 days.

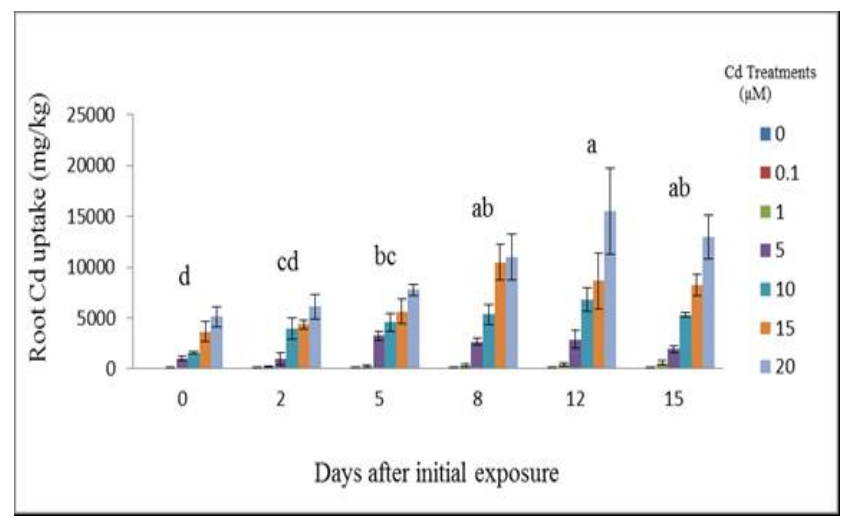

Figure 6. Cadmium uptake by wheat roots at different days after initial exposure to Cd. Day means with common letters do not differ significantly from other days $(p \leq 0.05)$

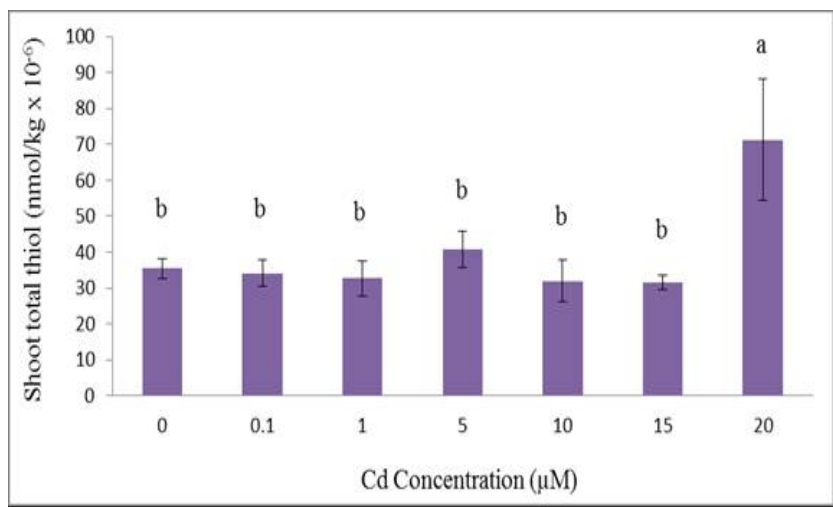

Figure 7. Total acid-soluble thiols of wheat shoots grown for 12 days at different $\mathrm{Cd}$ concentations. Treatment means with common letters do not differ significantly from each other $(p \leq 0.05)$

Figure 7 shows total acid - soluble thiols in wheat shoots for day 12 with measureable amounts $(0.000035 \pm$ $0.0000027 \mathrm{nmol} / \mathrm{kg}$ ) in the control. Plants exposed to 20 $\mu \mathrm{M} \mathrm{Cd}$ exhibited the greatest amount $(0.000071 \pm$ $0.0000016 \mathrm{nmol} / \mathrm{kg}$ ) of total acid - soluble thiols (Figure 7). There was a significant difference in total acid - soluble thiol contents between plants exposed to $20 \mu \mathrm{M} \mathrm{Cd}$ as compared to the control. There were no significant differences amongst $0.1,5,10$, and $15 \mu \mathrm{M}$ as compared to the control. Plants exposed to $5 \mu \mathrm{M} \mathrm{Cd}$ for 12 days had the second highest measurable amount $(0.0000408 \pm 0.0000051$ $\mathrm{nmol} / \mathrm{kg}$ ) of total acid - soluble thiols (Figure 7). Total acid soluble thiols ranged from the least $(0.000035 \pm 0.0000027)$ to greatest $(0.000071 \pm 0.0000016 \mathrm{nmol} / \mathrm{kg})$, respectively. Total acid - soluble thiols remained within the same average range of $0.000032 \pm 0.0000049 \mathrm{nmol} / \mathrm{kg}$ and then drastically increased for $20 \mu \mathrm{M}$ (Figure 7). Low levels of acid soluble thiols were present within wheat shoots.

Figure 8 displays the levels of total acid - soluble thiols in wheat roots exposed to $\mathrm{Cd}$ treatments for 12 days. Acid soluble thiols in wheat roots were present at greater levels compared to wheat shoots after 12 days of exposure. Plants exposed to $15 \mu \mathrm{M} \mathrm{Cd}$ had the highest level $(0.000033 \pm$ $0.0000094 \mathrm{nmol} / \mathrm{kg}$ ) of acid - soluble thiols (Figure 8). There were no significant differences in root total acid soluble contents among $\mathrm{Cd}$ treatments as compared to the control. Measureable amounts of total acid - soluble thiols in wheat roots persisted within the scale $0.000027 \pm$ $0.0000037 \mathrm{nmol} / \mathrm{kg}$. A comparison between root and shoot uptake in relation to phytochelatin contents showed that a sizeable amount of $\mathrm{Cd}$ were translocated to the shoots (data not shown).

Cadmium uptake was measured in relation to phytochelatin analysis with $20 \mu \mathrm{M}$ showing the greatest uptake, $27259.67 \pm 6339.97 \mathrm{mg} \mathrm{Cd} / \mathrm{kg}$. Remarkable amounts of $\mathrm{Cd}$ were translocated to the shoots. There was a significant difference in Cd uptake between plants exposed $20 \mu \mathrm{M} \mathrm{Cd}$ as compared to the control.

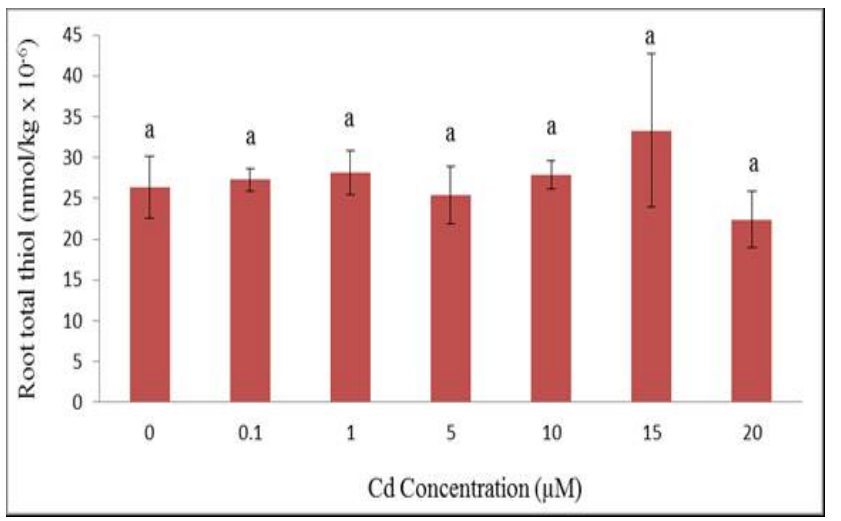

Figure 8 Total acid-soluble thiols of wheat roots grown for 12 days at different $\mathrm{Cd}$ concentrations. Treatment means with common letters do not differ significantly from each other $(p \leq 0.05)$

Metals such as cadmium are often in minute amounts in the soil. Research from earlier studies imply that plants may suffer from the effect of cadmium in the soil, if the total amount of cadmium is greater than $8 \mathrm{mg} / \mathrm{kg}$ and the bioavailable metal is greater than $0.001 \mathrm{mg} / \mathrm{kg}[18,19]$. The results shown in Figure 1 concur with this observation describing a decrease in plants biomass as $\mathrm{Cd}$ concentration increased. All plants survived and were tolerant to cadmium. However, Triticum aestivum L. plants exposed to the maximum concentration of $20 \mu \mathrm{M} \mathrm{Cd}$ exhibited Cd toxicity symptoms.

Metal concentration, type, and length of exposure to metal, whether the metal solution is reintroduced over time or not, and type of substrate can remarkably transform metal availability for the plant[20]. Cadmium did not only accumulate in the roots but was also translocated to the shoots suggesting that wheat plants are good accumulators of cadmium (Figure 5 and 6). Cadmium is a very soluble metal that moves in plants and translocates to aboveground parts especially posing a threat to the food supply chain. The accumulations in wheat roots were greater than shoots (Figure 5 and 6). This indicated that the roots are a barrier for metal translocation and the roots also protect the edible parts from toxic heavy metal contamination[21]. Even though most of the cadmium was taken up into the 
roots, a considerable amount was still found in the shoots. A key distinguishing factor of an accumulating plant that extracts metal from the soil is that it must have a high biomass yield[22]. Our results showed that Triticum aestivum L. had a vast biomass yield and were able to withstand the toxic effects of cadmium (Figures 1 and 4).

A hydroponic system was used to carry out this research to eliminate the factor that different metals inhibit the accumulation of other metals naturally in the soil. Cheng et al. [23] discussed that the interaction between heavy metals in the natural environment presented a difficult approach. Plants at 15 days after initial exposure to $20 \mu \mathrm{M}$ of cadmium displayed discoloration, yellowing (Figure 3), and stunting of growth, which concur with the work of Ouzounidou et al.[24]. The growth decline and also the inhibition of chlorophyll synthesis and photosynthesis detected in the upper plant parts appeared primarily due to unintended $\mathrm{Cd}$ effects on the content of essential nutrients[24]. Cadmium has major effects on different metabolic mechanisms in plants from stomata opening, and transpiration[25]. Cadmium can interfere with plant uptake, water transport, and use of essential elements. We presented data only on glutathione (GSH) in reference to Anderson[17] who indicated that the determination of GSSG is difficult because it is normally present in very small amounts, the volatility and dangerous nature of reagents, and the requisite to minimize oxidation of GSH. Thiols are the detoxifying agents in plants that are used to tolerate heavy metals[26]. The results of our data showed that total acid-soluble thiols are also being synthesized in the non - metal treatment, which suggest that thiols may not be the mechanism that govern metal detoxification in wheat plants (Figures 7 and 8). Roots are important for the absorption of heavy metals, and this is the primary cause why non-protein thiol compounds which are synthesized from glutathione in response to stress dynamics are primarily present in roots[27] (Figure 8).

\section{Conclusions}

The experiment suggests that wheat is an efficient $\mathrm{Cd}$ accumulating plant. All plants survived and were tolerant to cadmium except those exposed to $20 \mu \mathrm{M} \mathrm{Cd}$ as exhibited by their phytotoxic symptoms. Metal accumulation were not only sequestered in the roots but also translocated to the shoots suggesting that wheat plants are good accumulators of cadmium. We can conclude that the translocation of $\mathrm{Cd}$ from root to shoot is through the xylem which is the main process in shoot accumulation. Although wheat plant growth and uptake were affected, the plants demonstrated tolerance to cadmium contamination which may aid in their colonization in cadmium-polluted environments. It appeared that total thiols which represented phytochelatin synthesis can partially explain the tolerance of wheat to $\mathrm{Cd}$. Such phytochelatin synthesis was triggered at a relatively high $\mathrm{Cd}$ treatment $(20 \mu \mathrm{M})$ which was more evident in shoot rather than in the root.

\section{ACKNOWLEDGEMENTS}

This publication was made possible by support provided by the U.S. National Aeronautics and Space Administration (NASA) through The University of Mississippi (UM Subcontract No. 11-08-010 to Jackson State University; M.Begonia. P. I.) under the terms of Agreement No. NNG05GJ72H. The opinions expressed herein are those of the authors and do not necessarily reflect the views of NASA or The University of Mississippi. We acknowledge the partial financial support of the Department of Biology, CSET, JSU.

\section{REFERENCES}

[1] Jamali, M. K., Kazi, T. G., Arain, M. B., Afridi, H. I., Jalbani, N., Kandhro, G. A., and Baig, J. A. 2009. Heavy metal accumulation in different varieties of wheat (Triticum aestivum L). grown in soil amended with domestic sewage sludge. J. Hazardous Mat. 164(2-3):1386-1391.

[2] Khoshgoftarmanesh, A. H., and Chaney, R. L. 2007. Preceding crop affects grain cadmium and zinc of wheat grown in saline soils of Central Iran. J. Environ. Quality 36(4): 1132-1136. doi: 10.2134/jeq2006.0276.

[3] Sayyad, G., Afyuni, M., Mousavi, S., Abbaspour, K., Hajabbasi, M., Richards, B., and Schulin, R. 2009. Effects of cadmium, copper, lead, and zinc contamination on metal accumulation by safflower and wheat. Soil Sediment Contam. 18: 216-228. doi: 10.1080/15320380802660248.

[4] Salt, D. E., Smith, R. D., and Raskin, I. 1998. Phytoremediation. Annu. Rev. Plant Physiol. Plant Mol. Biol. 49(1): 643-668. doi: 10.1146/annurev.arplant.49.1.643.

[5] Peng, K. J., Luo, C. L., Chen, Y. H., Wang, G. P., Li, X. D., and Shen, Z. G. 2009. Cadmium and other metal uptake by Lobelia chinensis and Solanum nigrum from contaminated soils. Bull. Environ. Contam. Toxicol. 83(2): 260-264. doi: 10.1007/s00128-009-9701-0.

[6] Alonso-Castro, A.J., Carranza-Àlvarez, C., Alfaro-De la Torre, M.C., Chávez-Guerrero, L., Gardcía-De la Cruz, R.F. 2009. Removal and accumulation of cadmium and lead by Typha latifolia exposed to single and mixed metal solutions. Arch. Environ. Contam. Toxicol 57:688-696.

[7] Grill, E., Loffler, S., Winnacker, E., and Zenk, M. 1989. Phytochelatins, the heavy-metal-binding peptides of plants, are synthesized from glutathione by a specific gamma -glutamylcysteine dipeptidyl transpeptidase phytochelatin synthase. Proc. Natl. Acad. Sci. 86(18): 6838-6842. doi: 10.1073/pnas.86.18.6838.

[8] Cobbett, C. 2000. Phytochelatins and their roles in heavy metal detoxification. Plant Physiol. 123: 825-832.

[9] Bleeker, P. M., Schat, H., Vooijs, R., Verkleij, J. C., \& Ernst, W. O. (2003). Mechanisms of arsenate tolerance in Cytisus striatus. New Phytol. 157(1): 33-38. doi: 10.1046/j.14698137. 2003.00542.x

[10] Salati, S., Quadri, G., Tambone, F., and Adani, F. 2010. Fresh organic matter of municipal solid waste enhances phytoex- 
traction of heavy metals from contaminated soil. Environ. Pollut. 158: 1899-1906.

[11] Bidlack, J. E., and Jansky, S. 2011. Stern's Introductory plant biology, 12th ed. McGraw-Hill, NY. 622 pp.

[12] Ghnaya, A., Charles, G., Hourmant, A., Hamida, J., and Branchard, M. 2007. Morphological and physiological characteristics of rapeseed plants regenerated in vitro from thin cell layers in presence of zinc. Comptes Rendus Biol. 330(10): 728-734.

[13] ATSDR .2007. CERCLA Priority list of hazardous substances. ATSDR Home. Retrieved March 22, 2011, from http://www.atsdr.cdc.gov/cercla/07list.html.

[14] U. S. Environmental Protection Agency. 1990. Test methods for evaluating solid wastes. EPA SW-846, EPA, Washington D. C.

[15] Keltjens, W. G., and Van Beusichem, M. L. 1998. Phytochelatins as biomarkers for heavy metal toxicity in maize: Single metal effects of copper and cadmium. J. Plant Nutr. 21(4): 635-648. doi: 10.1080/01904169809365431.

[16] Ellman, G. 1959. Tissue sulfhydryl groups. Arch. Biochem. Biophys. 82(1):70-77. doi: 10.1016/0003-9861(59)90090-6.

[17] Anderson, M. E. 1985. Tissue glutathione. Pages 317-323 in R. Greenwald (ed.). CRC Handbook of Methods for Oxygen Radical Research. CRC Press, Boca Raton, FL.

[18] Pahlsson, A. B. 1989. Toxicity of heavy metals (Zn, Cu, Cd, $\mathrm{Pb})$ to vascular plants. Water Air Soil Pollut. 47(3-4): 287-319. doi: 10.1007/BF00279329.

[19] Ghosh, M., and Singh, S. 2005. A comparative study of cadmium phytoextraction by accumulator and weed species. Environ. Pollut. 133(2):365-371.
[20] Zacchini, M., Pietrini, F., Scarascia Mugnozza, G., Iori, V., Pietrosanti, L., and Massacci, A. 2009. Metal tolerance, accumulation and translocation in poplar and willow clones treated with cadmium in hydroponics. Water Air Soil Pollut. 197(1-4): 23-34. doi: 10.1007/s11270-008-9788-7.

[21] Liu, W., Liu, J., Wu, M., Li, Y., Zhao, Y., and Li, S. 2009. Accumulation and translocation of toxic heavy metals in winter wheat (Triticum aestivum L.) growing in agricultural soil of Zhengzhou, China. Bull. Environ. Contam. Toxicol. 82(3): 343-347. doi: 10.1007/s00128-008-9575-6.

[22] Sekara, A., Poniedzialek, M., Ciura, J., and Jedrszezyk, E. 2005. Cadmium and lead accumulation and distribution in the organs of nine crops: Implications for phytoremediation. Polish J. Environ. Studies 14(4): 509-516.

[23] Cheng, W., Zhang, G., Yao, H., Wu, W., and Xu, M. 2006. Genotypic and environmental variation in cadmium, chromium, arsenic, nickel, and lead concentrations in rice grains. J. Zhejiang. Uni. Sci. B.(7):565-571.doi:10.1631/. /jzus. 2006. B0565.

[24] Ouzounidou, G., Moustakas, M., and Eleftheriou, E. P. 1997. Physiological and ultrastructural effects of cadmium on wheat (Triticum aestivum L.) leaves. Arch. Environ. Contam. Toxicol. 32(2): 154-160. doi: 10.1007/s002449900168.

[25] Benavides, M. P., Gallego, S. M., and Tomaro, M. L. 2005. Cadmium toxicity in plants. Brazilian J. Plant Physiol. 17(1): 21-34 doi: 10.1590/S1677-04202005000100003.

[26] Zhang, W., Cai, Y., Downum, K., and Ma, L. 2004. Thiol synthesis and arsenic hyperaccumulation in Pteris vittata (Chinese brake fern). Environ. Pollut. 131(3): 337-345. doi: 10.1016/j.envpol.2004.03.010.

[27] Potters, G., De Gara, L., Asard, H., and Horemans, H. 2002. Ascorbate and glutathione: Guardians of the cell cycle, partners in crime. Plant Physiol. Biochem. 40: 537-548. 